Journal of Mathematics and Statistics 2 (4): 460-463, 2006

ISSN 1549-3644

(C) 2006 Science Publications

\title{
The Existence and Unbounded Extension of the Solutions of the Systems with Stochastic Impulse Action
}

\author{
Ali Mahmud Ateiwi and Iryna Volodymyrivna Komashynska \\ Department of Mathematics and Statistics, Faculty of Science, Al-Hussein Bin Talal University \\ P.O. Box (20), Ma'an-Jordan
}

\begin{abstract}
In terms of Liapunov's functions we received the conditions of the existence and unbounded extension of the solutions of the systems with stochastic impulse action.
\end{abstract}

Key words: The moment of impulse, random process, solution, Liapunov's function

\section{INTRODUCTION}

The system with impulse action is the convenient mathematical model to describe natural processes which are the subjects of immediate influence during their evolution. Such systems are intensively studied nowadays by many mathematicians. The famous monograph ${ }^{[1]}$ may serve as the summary of the research conducted in this field. It promotes the continuing stream of the works on this topic.

At the same time the impulse systems in Banach spaces $^{[2]}$, impulse differential inclusions ${ }^{[3]}$, partial differential equations with impulse action etc. are being studied.

Meanwhile, in real life the magnitude of the impulse, as a rule, is unknown and may be random. Taking this randomness into consideration leads us to the mathematical models, which are the differential equations with random impulse action. One of the first works devoted to such stochastic influence was ${ }^{[5]}$. It describes a linear system with constant coefficients, which is the subject of random impulse at the fixed moments of time. Separate questions of this theory are described in ${ }^{[5]}$ and $^{[6]}$.

In this work we study the qualitative behavior of the solutions of impulse systems with stochastic right part and stochastic impulses, for instance, the question of unbounded extension of them to the right.

Introducing the problem: Let $(\Omega, \mathrm{F}, \mathrm{P})-$ be the probability space, $\xi(\mathrm{t})$-random process on $[0, \infty)$, which is defined on the probability space and is $\mathrm{R}^{\mathrm{d}}$ - valued. We consider the system of differential equations with stochastic right part and stochastic impulse action at the fixed moments of time:

$$
\left\{\begin{array}{c}
\frac{d x}{d t}=F(t, x, \xi(t)), t=t_{i} \\
\left.\Delta x\right|_{t=t_{i}}=x\left(t_{i}+0\right)-x\left(t_{i}-0\right)=I_{i}\left(x\left(t_{i}\right), \omega\right)
\end{array}\right.
$$

where $t \geq 0, x \in R^{n}, I_{i}(x, \omega)$ - is the sequence of random values in $R^{n}$ for $\mathrm{x} \in \mathrm{R}^{\mathrm{n}} .\left\{\mathrm{t}_{\mathrm{i}}\right\}$ - the sequence of the moments of impulse action, such that $\lim _{i \rightarrow \infty} t_{i}=\infty$

We will consider the random process $x(t)$ to be the solution of (1) if on $\left(t_{i}, t_{i+1}\right]$ it is an absolutely continuous with probability 1 function and almost everywhere (with respect to the Lebegue's measure) satisfies on $\left(t_{i}, t_{i+1}\right]$ the first equation of (1) and at the moments $t_{i}$ it satisfies the jump condition : $x\left(t_{i}+0\right)=x\left(t_{i}-0\right)+I_{i}\left(x\left(t_{i}\right), \omega\right)$. We will be studying the extension of such solutions on half-axe $t \geq 0$.

Some additional facts and statements: We will state some facts that would be essential in future.

Concerning all the Liapunov's functions that we will be using in future, we will demand for them to be absolutely continuous on $t$ and uniformly continuous on $x$ in the neighborhood of every point and satisfy the Lipshitz condition on $x$ :

$$
\left|\mathrm{V}\left(\mathrm{t}, \mathrm{x}_{1}\right)-\mathrm{V}\left(\mathrm{t}, \mathrm{x}_{2}\right)\right| \leq \mathrm{L}\left|\mathrm{x}_{1}-\mathrm{x}_{2}\right|
$$

in the domain $|x| \leq R, t \in[0, T]$, where $L$ depends on $\mathrm{R}$ and $\mathrm{T}$. In this case, we say $\mathrm{V} \in \mathrm{C}$. If the constant $\mathrm{L}$ does not depend on the domain, we will say $\mathrm{V} \in \mathrm{C}_{0}$.

It is clear, that if $\mathrm{V} \in \mathrm{C}$ and the function $\mathrm{x}(\mathrm{t})-$ is absolutely continuous, then $\mathrm{V}(\mathrm{t}, \mathrm{x}(\mathrm{t}))$ is also absolutely continuous and the Liapunov's operator, defined by the formula

$$
\frac{d^{0} V(t, x)}{d t}=\lim _{h \rightarrow 0} \frac{V(t+h, x(t+h))-V(t, x)}{h}
$$

in this case looks like:

$$
\frac{\mathrm{d}^{0} \mathrm{~V}(\mathrm{t}, \mathrm{x})}{\mathrm{dt}}=\left.\frac{\mathrm{d}}{\mathrm{dt}} \mathrm{V}(\mathrm{t}, \mathrm{x}(\mathrm{t}))\right|_{\mathrm{x}(\mathrm{t})=\mathrm{x}}
$$

Furthermore, we will need the following lemma about the linear inequalities.

Corresponding Author: Iryna Volodymyrivna Komashynska, Department of Mathematics and Statistics, Faculty of Science, Al-Hussein Bin Talal University, P.O.Box (20), Ma'an-Jordan 
Lemma 1: Let $y(t)-$ be an absolutely continuous function on $t \geq t_{0}$, derivative of which $\frac{d y}{d t}$ for almost all $t \geq t_{0}$ satisfies the inequality $\frac{d y}{d t} \leq A(t) y+B(t)$, where $\mathrm{A}(\mathrm{t}), \mathrm{B}(\mathrm{t})$ - are almost everywhere continuous functions, integrated on every finite interval .

Then for $t \geq t_{0}$ the following inequality holds

$$
\mathrm{y}(\mathrm{t}) \leq \mathrm{y}_{0} \exp \left\{\int_{\mathrm{t}_{0}}^{\mathrm{t}} \mathrm{A}(\mathrm{s}) \mathrm{ds}\right\}+\int_{\mathrm{t}_{0}}^{\mathrm{t}} \exp \left\{\int_{\mathrm{t}_{0}}^{\mathrm{t}} \mathrm{A}(\mathrm{u}) \mathrm{du}\right\} \mathrm{B}(\mathrm{s}) \mathrm{ds} .
$$

The proof can be deduced from the standard methods of differential inequalities.

\section{RESULTS}

First of all, for the system (1), considering the behavior of its solutions, for instance, the fact, that on $\left(\mathrm{t}_{\mathrm{i}}, \mathrm{t}_{\mathrm{i}+1}\right]$ they are the solutions of the system without impulses, the similar way as in $^{[6]}$ we may receive the theorem of existence and uniqueness of its solutions. The following theorem takes place.

Theorem 1: Let $\xi(\mathrm{t})$-be the measurable separable random process, defined for $\mathrm{t} \geq \mathrm{t}_{0}, \mathrm{~F}(\mathrm{t}, \mathrm{x}, \mathrm{z}),\left(\mathrm{x} \in \mathrm{R}^{\mathrm{n}}, \mathrm{t} \geq 0, \mathrm{z} \in \mathrm{R}^{\mathrm{k}}\right)-$ Borel

measurable function with respect to the variables $(\mathrm{t}, \mathrm{x}, \mathrm{z})$, such that:

1. There exists the random process $\mathrm{L}(\mathrm{t})$, which is absolutely integrated on any bounded interval on half - axe $t \geq 0$ such that for any $x_{i} \in R^{n}$

$$
\left|F\left(t, x_{1}, \xi(t)\right)-F\left(t, x_{2}, \xi(t)\right)\right| \leq L(t)\left|x_{1}-x_{2}\right|
$$

2. Random process $\mathrm{F}(\mathrm{t}, 0, \xi(\mathrm{t}))$ absolutely integrated on any finite interval on half - axe $t \geq 0$.

3. $\quad \mathrm{I}_{\mathrm{i}}(\mathrm{x}, \omega)$-are measurable on $x$ functions for every $i$. Then there exists the solution of Cauchy problem for the system (1) with the initial condition $\mathrm{x}\left(\mathrm{t}_{0}\right)=\mathrm{x}_{0}(\omega)$ which is unique for each trajectory and is the piecewise absolutely continuous random process for $\mathrm{t} \geq 0$.

Therefore, this theorem gives the conditions of existence, uniqueness and unbounded extension to the right of the solutions of the system (1). But the global Lipshitz condition (2) doesn't hold in many actual cases. For instance, the solutions of the equation $\&=-x^{3}$ exist, they are unique and unboundedly extended to the right for $t \geq 0$, at the same time it is obvious, that the condition (2) the Theorem 1 holds only locally.

That's why, it would be desirable to impose more weak conditions of existence and uniqueness. The following theorem takes place.
Theorem 2: Let there exist the family of random variables $\tau_{R}(\omega)$ such that $\tau_{R}(\omega) \rightarrow \infty$ for $R \rightarrow \infty$, with probability 1 and for every solution of the Cauchy problem the priory estimate holds true:

$\inf _{t \geq 0}\{|x(t)| \geq R\} \geq \tau_{R}(\omega)$

with probability 1 . If $\mathrm{F}(\mathrm{t}, 0, \xi(\mathrm{t}))$ is locally absolutely integrated with probability 1 on the half-axe $t \geq 0$ and $\mathrm{F}(\mathrm{t}, \mathrm{x}, \xi(\mathrm{t}))$ satisfies the local Lipshitz condition and condition 3 of the Theorem 1, then with the probability 1 , the solution of Cauchy problem with the initial conditions $\mathrm{x}\left(\mathrm{t}_{0}, \omega\right)=\mathrm{x}_{0}(\omega)$ exists and is a unique, piecewise continuous random process for $t \geq 0$.

The proof of this theorem is similar to the proof of the corresponding theorem for the system without impulses $^{[6]}$, considering the definition of the solutions of impulse system.

Although the conditions in this theorem are weaker compared to the conditions in Theorem1 (the Lipshitz condition has only local character), they are not effective enough, for they demand checking the condition (3), which itself implies the ability to solve the system (1). Nevertheless, for the systems of a special type, which linearly involve the random variables, it is possible to give rather effective conditions for the unbounded extension of the solutions in terms of Liapunov's functions.

Let us consider the system of a special type:

$\frac{\mathrm{dx}}{\mathrm{dt}}=\mathrm{F}(\mathrm{t}, \mathrm{x})+\sigma(\mathrm{t}, \mathrm{x}) \xi(\mathrm{t}), \mathrm{t} \neq \mathrm{t}_{\mathrm{i}}$
$\left.\Delta \mathrm{x}\right|_{\mathrm{t}=\mathrm{t}_{\mathrm{i}}}=\mathrm{I}_{\mathrm{i}}(\mathrm{x})+\mathrm{J}_{\mathrm{i}}(\mathrm{x}) \eta_{\mathrm{i}}(\omega), \mathrm{t}=\mathrm{t}_{\mathrm{i}}$

Here the functions $F, I_{i}$ and the matrixes $\sigma, J_{i}$ of the dimension $\mathrm{n} \times \mathrm{k}$ are defined, continuous for $\mathrm{t}>0, \mathrm{x} \in \mathrm{R}^{\mathrm{n}}, \xi(\mathrm{t})$ is $\mathrm{k}$-dimensional stochastic process, $\eta_{\mathrm{i}}$ is $\mathrm{k}$-dimensional random variables.

Along with (4) we will be considering the shortened system

$$
\begin{aligned}
& \frac{\mathrm{dx}}{\mathrm{dt}}=\mathrm{F}(\mathrm{t}, \mathrm{x}), \mathrm{t} \neq \mathrm{t}_{\mathrm{i}} \\
& \left.\Delta \mathrm{x}\right|_{\mathrm{t}=\mathrm{t}_{\mathrm{i}}}=\mathrm{I}_{\mathrm{i}}(\mathrm{x}), \mathrm{t}=\mathrm{t}_{\mathrm{i}}
\end{aligned}
$$

We will define $\frac{d^{(1)}}{d t}$ to be the Liapunov's operator for the system (4) and $\frac{\mathrm{d}^{(0)}}{\mathrm{dt}}$ to be the Liapunov's operator for the shortened determined system (5).

Lemma 2: If $\mathrm{V}(\mathrm{t}, \mathrm{x}) \in \mathrm{C}_{0}$, then for almost every $t$ the following inequalities hold true with the probability 1

$$
\frac{d^{(1)} V(t, x)}{d t} \leq \frac{d^{(0)} V(t, x)}{d t}+L\|\sigma(t, x)\|\|\xi(t)\|, t \neq t_{i}
$$




$$
\begin{aligned}
& \mathrm{V}\left(\mathrm{t}_{\mathrm{i}}, \mathrm{x}+\mathrm{I}_{\mathrm{i}}(\mathrm{x})+\mathrm{J}_{\mathrm{i}}(\mathrm{x}) \eta_{\mathrm{i}}(\omega)\right) \\
& \leq \mathrm{V}\left(\mathrm{t}_{\mathrm{i}}, \mathrm{x}+\mathrm{I}_{\mathrm{i}}(\mathrm{x})\right)+\mathrm{L}\left|\eta_{\mathrm{i}}\right| \mid \mathrm{J}_{\mathrm{i}}(\mathrm{x}) \|, \mathrm{t}=\mathrm{t}_{\mathrm{i}}
\end{aligned}
$$

Proof: The first statement in (6) follows from the corresponding statement $\mathrm{in}^{[6]}$. The second follows from the following:

$$
\begin{aligned}
& \mathrm{V}\left(\mathrm{t}_{\mathrm{i}}, \mathrm{x}+\mathrm{I}_{\mathrm{i}}(\mathrm{x})+\mathrm{J}_{\mathrm{i}}(\mathrm{x}) \eta_{\mathrm{i}}(\omega)\right) \\
& \leq \mathrm{V}\left(\mathrm{t}_{\mathrm{i}}, \mathrm{x}+\mathrm{I}_{\mathrm{i}}(\mathrm{x})+\mathrm{J}_{\mathrm{i}}(\mathrm{x}) \eta_{\mathrm{i}}\right)-\mathrm{V}\left(\mathrm{t}_{\mathrm{i}}, \mathrm{x}+\mathrm{I}_{\mathrm{i}}(\mathrm{x})\right)+ \\
& +\mathrm{V}\left(\mathrm{t}_{\mathrm{i}}, \mathrm{x}+\mathrm{I}_{\mathrm{i}}(\mathrm{x})\right) \leq \mathrm{V}\left(\mathrm{t}_{\mathrm{i}}, \mathrm{x}+\mathrm{I}_{\mathrm{i}}(\mathrm{x})\right)+\mathrm{L}\left|\eta_{\mathrm{i}}\right|\left\|\mathrm{J}_{\mathrm{i}}(\mathrm{x})\right\| .
\end{aligned}
$$

Now we will state the main result of this study.

Theorem 3: Let $\xi(\mathrm{t})$ be locally absolutely integrated stochastic process for $t \geq 0$, the vector $F$ and the matrix $\sigma$ satisfy the local Lipshitz condition with respect to $\mathrm{X}$ and $F(t, 0)$ - is locally absolutely integrated

$$
\begin{aligned}
& \sup _{\mathrm{R}^{\mathrm{n}} \times\left\{\mathrm{it} \geq \mathrm{t}_{0}\right\}}\|\sigma(\mathrm{t}, \mathrm{x})\| \leq \mathrm{C}_{1} \\
& \left\|\mathrm{~J}_{\mathrm{i}}(\mathrm{x})\right\| \leq \mathrm{BV}\left(\mathrm{t}_{\mathrm{i}}, \mathrm{x}\right), \mathrm{B}=\text { const }>0, \mathrm{x} \in \mathrm{R}^{\mathrm{n}}, \mathrm{i} \geq 0
\end{aligned}
$$

Suppose that for system (5) there exist the Liapunov's function $\mathrm{V}(\mathrm{t}, \mathrm{x}) \in \mathrm{C}_{0}$, which satisfies the following conditions:

$$
\begin{aligned}
& \mathrm{V}_{\mathrm{R}}=\inf _{\substack{|\mathrm{x}|>\mathrm{R} \\
\mathrm{t} \geq \mathrm{t}_{0}}} \mathrm{~V}(\mathrm{t}, \mathrm{x}) \rightarrow \infty, \mathrm{R} \rightarrow \infty \\
& \frac{\mathrm{d}^{(0)} \mathrm{V}}{\mathrm{dt}} \leq \mathrm{C}_{2} \mathrm{~V}(\mathrm{t}, \mathrm{x}), \\
& \mathrm{V}\left(\mathrm{t}_{\mathrm{i}}, \mathrm{x}+\mathrm{I}_{\mathrm{i}}(\mathrm{x})\right)-\mathrm{V}\left(\mathrm{t}_{\mathrm{i}}, \mathrm{x}\right) \leq \mathrm{C}_{3} \mathrm{~V}\left(\mathrm{t}_{\mathrm{i}}, \mathrm{x}\right)
\end{aligned}
$$

where $\mathrm{C}_{2}, \mathrm{C}_{3}$ are some positive constants, $\mathrm{t} \geq \mathrm{t}_{0}, \mathrm{x} \in \mathrm{R}^{\mathrm{n}}$.

Then there exists the condition of the Cauchy problem for the system (4) with the initial conditions $\mathrm{x}\left(\mathrm{t}_{0}\right)=\mathrm{x}_{0}(\omega)$, which is a piecewise absolutely continuous stochastic process for $t \geq t_{0}$.

Proof: Under the conditions imposed in this theorem, it is obvious that the conditions of the local existence and uniqueness for each trajectory hold true, therefore, there exists the solution of (4) such that $x\left(t_{0}, x_{0}\right)=x_{0}(\omega)$. We will show that it may be unboundedly extended to the right for $t \geq t_{0}$. The conditions in this theorem imply, that the function $\mathrm{V}\left(\mathrm{t}, \mathrm{x}\left(\mathrm{t}, \mathrm{x}_{0}\right)\right)$ is piecewise absolutely continuous on $t$.

Without the loss of generality, we may consider $t_{0}=0$. Then, according to ${ }^{[6]}$, before the moment of first impulse on $\left[0, t_{1}\right]$ we have an estimate for almost all $\mathrm{t}, \omega$ :

$$
\begin{aligned}
& \frac{\mathrm{dV}\left(\mathrm{t}, \mathrm{x}\left(\mathrm{t}, \mathrm{x}_{0}\right)\right)}{\mathrm{dt}} \leq \frac{\mathrm{d}^{(0)} \mathrm{V}\left(\mathrm{t}, \mathrm{x}\left(\mathrm{t}, \mathrm{x}_{0}\right)\right)}{\mathrm{dt}} \\
& +\mathrm{L} \| \sigma\left(\mathrm{t}, \mathrm{x}\left(\mathrm{t}, \mathrm{x}_{0}\right) \||\xi(\mathrm{t})| \leq \mathrm{C}_{2} \mathrm{~V}(\mathrm{t}, \mathrm{x})+\mathrm{LC}_{1}|\xi(\mathrm{t})|\right.
\end{aligned}
$$

For $t=t_{1}$ from the second inequality in (9) we get

$$
\begin{aligned}
& \mathrm{V}\left(\mathrm{t}_{1}, \mathrm{x}\left(\mathrm{t}_{1}, \mathrm{x}_{0}\right)+\mathrm{I}_{\mathrm{i}}\left(\mathrm{x}\left(\mathrm{t}_{1}, \mathrm{x}_{0}\right)\right)+\mathrm{J}_{1}\left(\mathrm{x}\left(\mathrm{t}_{1}, \mathrm{x}_{0}\right)\right) \eta_{1}(\omega)\right) \\
& \leq \mathrm{V}\left(\mathrm{t}_{1}, \mathrm{x}\left(\mathrm{t}_{1}, \mathrm{x}_{0}\right)+\mathrm{I}_{\mathrm{i}}\left(\mathrm{x}\left(\mathrm{t}_{1}, \mathrm{x}_{0}\right)\right)\right)+ \\
& +\mathrm{L}\left|\eta_{1}\right||| \mathrm{J}_{1}\left(\mathrm{x}\left(\mathrm{t}_{1}, \mathrm{x}_{0}\right)\right) \| \leq \mathrm{V}\left(\mathrm{t}_{1}, \mathrm{x}\left(\mathrm{t}_{1}, \mathrm{x}_{0}\right)+\mathrm{I}_{1}\left(\mathrm{x}\left(\mathrm{t}_{1}, \mathrm{x}_{0}\right)\right)\right) \\
& -\mathrm{V}\left(\mathrm{t}_{1}, \mathrm{x}\left(\mathrm{t}_{1}, \mathrm{x}_{0}\right)\right)+\mathrm{V}\left(\mathrm{t}_{1}, \mathrm{x}\left(\mathrm{t}_{1}, \mathrm{x}_{0}\right)\right)+\operatorname{LBV}\left(\mathrm{t}_{1}, \mathrm{x}\left(\mathrm{t}_{1}, \mathrm{x}_{0}\right)\right)\left|\eta_{1}\right| \leq \\
& \leq\left(\mathrm{C}_{3}+1\right) \mathrm{V}\left(\mathrm{t}_{1}, \mathrm{x}\left(\mathrm{t}_{1}, \mathrm{x}_{0}\right)\right)+\operatorname{BLV}\left(\mathrm{t}_{1}, \mathrm{x}\left(\mathrm{t}_{1}, \mathrm{x}_{0}\right)\right)\left|\eta_{1}\right|
\end{aligned}
$$

The inequality (10) and the lemma about the linear inequalities imply, that for $\mathrm{t} \in\left[0, \mathrm{t}_{1}\right]$

$$
\mathrm{V}\left(\mathrm{t}, \mathrm{x}\left(\mathrm{t}, \mathrm{x}_{0}\right)\right) \leq \mathrm{e}^{\mathrm{C}_{2}\left(\mathrm{t}-\mathrm{t}_{0}\right)}\left[\mathrm{V}\left(\mathrm{t}_{0}, \mathrm{x}_{0}\right)+\mathrm{LC}_{1} \int_{0}^{\mathrm{t}}|\xi(\mathrm{s})| \mathrm{ds}\right]
$$

That's why

$$
\begin{aligned}
& \mathrm{V}\left(\mathrm{t}_{1}+0, \mathrm{x}\left(\mathrm{t}_{1}+0, \mathrm{x}_{0}\right)\right) \leq\left(\left(\mathrm{C}_{3}+1\right)+\mathrm{BL}\left|\eta_{1}\right|\right) \mathrm{V}\left(\mathrm{t}_{1}, \mathrm{x}\left(\mathrm{t}_{1}, \mathrm{x}_{0}\right)\right) \leq \\
& \leq\left(\left(\mathrm{C}_{3}+1\right)+\mathrm{BL}\left|\eta_{1}\right|\right) \mathrm{e}^{\mathrm{C}_{2} \mathrm{t}_{1}}\left(\left(\mathrm{~V}\left(0, \mathrm{x}_{0}\right)+\mathrm{LC}_{2} \int_{0}^{\mathrm{t}_{1}}|\xi(\mathrm{s})| \mathrm{ds}\right)\right.
\end{aligned}
$$

Therefore, on $\left[\mathrm{t}_{1}, \mathrm{t}_{2}\right]$ the following estimate is true for all $t$

$$
\begin{aligned}
& \mathrm{V}\left(\mathrm{t}, \mathrm{x}\left(\mathrm{t}, \mathrm{x}_{0}\right)\right) \leq \mathrm{e}^{\mathrm{C}_{2}\left(\mathrm{t}-\mathrm{t}_{1}\right)}\left[( ( \mathrm { C } _ { 3 } + 1 ) + \mathrm { BL } | \eta _ { 1 } | ) \mathrm { e } ^ { \mathrm { C } _ { 2 } \mathrm { t } _ { 1 } } \left(\mathrm{V}\left(0, \mathrm{x}_{0}\right)+\right.\right. \\
& \left.\left.+\mathrm{LC}_{2} \int_{0}^{\mathrm{t}_{1}}|\xi(\mathrm{s})| \mathrm{ds}\right)+\mathrm{LC}_{1} \int_{\mathrm{t}_{1}}^{\mathrm{t}}|\xi(\mathrm{s})| \mathrm{ds}\right]
\end{aligned}
$$

Then

$$
\begin{aligned}
& \mathrm{V}\left(\mathrm{t}_{2}+0, \mathrm{x}\left(\mathrm{t}_{2}+0, \mathrm{x}_{0}\right)\right) \leq\left(\left(\mathrm{C}_{3}+1\right)+\mathrm{BL}\left|\eta_{2}\right|\right) \mathrm{V}\left(\mathrm{t}_{2}, \mathrm{x}\left(\mathrm{t}_{2}, \mathrm{x}_{0}\right)\right) \leq \\
& \leq\left(\mathrm{C}_{3}+1+\mathrm{BL}\left|\eta_{2}\right|\right) \mathrm{V}\left(\mathrm{t}_{2}, \mathrm{x}\left(\mathrm{t}_{2}, \mathrm{x}_{0}\right)\right) \leq\left(\mathrm{C}_{3}+1+\mathrm{BL}\left|\eta_{2}\right| \times\right. \\
& \times \mathrm{e}^{\mathrm{C}_{2}\left(\mathrm{t}_{2}-\mathrm{t}_{1}\right)}\left[\left(\mathrm{C}_{3}+1+\mathrm{BL}\left|\eta_{1}\right|\right) \mathrm{e}^{\mathrm{C}_{1} \mathrm{t}_{1}}\left(\mathrm{~V}\left(0, \mathrm{x}_{0}\right)+\mathrm{LC}_{1} \int_{\mathrm{t}_{1}}^{\mathrm{t}_{2}}|\xi(\mathrm{s})| \mathrm{ds}\right)\right] .
\end{aligned}
$$

So for $\mathrm{t} \in\left[\mathrm{t}_{2}, \mathrm{t}_{3}\right]$ we have

$$
\begin{aligned}
& \mathrm{V}\left(\mathrm{t}, \mathrm{x}\left(\mathrm{t}, \mathrm{x}_{0}\right)\right) \leq \mathrm{e}^{\mathrm{C}_{2}\left(\mathrm{t}-\mathrm{t}_{1}\right)}\left(\mathrm{C}_{3}+1+\mathrm{BL}\left|\eta_{1}\right|\right) \mathrm{e}^{\mathrm{C}_{2}\left(\mathrm{t}_{2}-\mathrm{t}_{1}\right)} \times \\
& \times\left[\left(\mathrm{C}_{3}+1\right)+\mathrm{BL}\left|\eta_{1}\right|\right) \mathrm{e}^{\mathrm{C}_{1} \mathrm{t}_{1}}\left(\mathrm{~V}\left(0, \mathrm{x}_{0}\right)\right. \\
& \left.\left.+\mathrm{LC}_{2} \int_{0}^{\mathrm{t}_{1}}|\xi(\mathrm{s})| \mathrm{ds}\right)+\mathrm{LC}_{1} \int_{\mathrm{t}_{1}}^{\mathrm{t}_{2}}|\xi(\mathrm{s})| \mathrm{ds}\right]
\end{aligned}
$$

Similarly, for all $t \in\left[t_{n}, t_{n+1}\right]$ for $n \geq 1$ we have

$$
\begin{aligned}
& \mathrm{V}\left(\mathrm{t}, \mathrm{x}\left(\mathrm{t}, \mathrm{x}_{0}\right)\right) \leq \mathrm{e}^{\mathrm{C}_{2}\left(\mathrm{t}-\mathrm{t}_{\mathrm{n}}\right)}\left\{\left(\mathrm{C}_{3}+1+\mathrm{BL}\left|\eta_{\mathrm{n}}\right|\right) \mathrm{e}^{\mathrm{C}_{2}\left(\mathrm{t}-\mathrm{t}_{\mathrm{n}-1}\right)} \times\right. \\
& \times\left[\left(\mathrm{C}_{3}+1\right)+\mathrm{BL}\left|\eta_{\mathrm{n}-1}\right|\right) \mathrm{e}^{\mathrm{C}_{2}\left(\mathrm{t}_{\mathrm{n}-1}-\mathrm{t}_{\mathrm{n}-2}\right)} \times\left(\ldots \mathrm { e } ^ { \mathrm { C } _ { 1 } \mathrm { t } _ { 1 } } \left(\mathrm{V}\left(0, \mathrm{x}_{0}\right)\right.\right. \\
& \left.\left.\left.+\mathrm{LC}_{2} \int_{0}^{\mathrm{t}_{1}}|\xi(\mathrm{s})| \mathrm{ds}\right)+\mathrm{LC}_{1} \int_{\mathrm{t}_{1}}^{\mathrm{t}_{2}}|\xi(\mathrm{s})| \mathrm{ds}+\ldots+\mathrm{LC}_{1} \int_{\mathrm{t}_{\mathrm{n}}}^{\mathrm{t}}|\xi(\mathrm{s})| \mathrm{ds}\right]\right\}
\end{aligned}
$$

We will denote the right part of this equality as $\mathrm{K}(\mathrm{t})$ and the solution of the equation

$\mathrm{K}(\mathrm{t})=\mathrm{V}_{\mathrm{r}}$

will be denoted as $\tau_{\mathrm{R}}(\omega)$.

As far as $\xi(t)$ is locally absolutely integrated and the number of impulses on any bounded interval is finite, the condition (8) implies that $\tau_{\mathrm{R}} \rightarrow \infty, \mathrm{R} \rightarrow \infty$ with probability 1 . Considering (8) we have $\inf _{\mathrm{t}}\left\{\left|\mathrm{x}\left(\mathrm{t}, \mathrm{t}_{0}\right)\right| \geq \mathrm{R}\right\} \geq \tau_{\mathrm{R}} \rightarrow \infty, \mathrm{R} \rightarrow \infty$ 
The relation (16) together with Theorem2 completes the proof.

To exemplify the application of this theorem, we will look at the perturbed Linear equation with impulse action

$$
\begin{aligned}
& \mathrm{x}^{\prime \prime}+\mathrm{f}(\mathrm{x}) \mathrm{x}^{\prime}+\mathrm{g}(\mathrm{x})=\sigma\left(\mathrm{x}, \mathrm{x}^{\prime}\right) \xi(\mathrm{t}), \mathrm{t} \neq \mathrm{t}_{\mathrm{i}} \\
& \left.\Delta \mathrm{x}^{\prime}\right|_{\mathrm{t}=\mathrm{t}_{\mathrm{i}}}=\mathrm{I}_{\mathrm{i}}\left(\mathrm{x}, \mathrm{x}^{\prime}\right)+\mathrm{J}_{\mathrm{i}}\left(\mathrm{x}, \mathrm{x}^{\prime}\right) \eta_{\mathrm{i}}(\omega)
\end{aligned}
$$

It describes the process on the 'output' of many actual radio technical systems, which receive random signal on the 'input' and during the process of evolution they are influenced by random impulse forces. For instance, if $f(x)=x^{2}-1, g(x)=x, \sigma\left(x, x^{\prime}\right)=1$ we get the well-known Van-der-Pole equation. Let the function $f$ be bounded from below and the following conditions hold true:

$$
\left|\sigma\left(\mathrm{x}, \mathrm{x}^{\prime}\right)\right| \leq \mathrm{C}_{1},\left|\frac{\mathrm{g}(\mathrm{x})}{\mathrm{x}}\right| \leq \mathrm{C}_{2}, \mathrm{I}_{\mathrm{i}}^{2}\left(\mathrm{x}, \mathrm{x}^{\prime}\right) \leq \mathrm{K}\left(\mathrm{x}^{2}+\mathrm{x}^{\prime 2}\right) .
$$

Let's show, that the conditions of the Theorem 3 are satisfied. Considering the equivalent to (17) system, we get

$$
\begin{aligned}
& \frac{d x}{d t}=y, t \neq t_{i} \\
& \frac{d y}{d t}=-f(x) y-g(x)+\sigma(x, y) \xi(t), t \neq t_{i} \\
& \left.\Delta y\right|_{t=t_{i}}=I_{i}(x, y)+J_{i}(x, y) \eta_{i}(\omega)
\end{aligned}
$$

For the given system we introduce the Liapunov's function $\quad \mathrm{V}(\mathrm{x}, \mathrm{y})=\sqrt{\mathrm{x}^{2}+\mathrm{y}^{2}} \in \mathrm{C}_{0}$. If $\left|J_{i}(x, y)\right| \leq A \sqrt{x^{2}+y^{2}}$, then the given function satisfies the conditions of the theorem.

Really,

$$
\begin{aligned}
& \frac{\mathrm{d}^{0} \mathrm{~V}}{\mathrm{dt}}=\frac{\mathrm{xy}}{\sqrt{\mathrm{x}^{2}+\mathrm{y}^{2}}}+\frac{\mathrm{yy}^{\prime}}{\sqrt{\mathrm{x}^{2}+\mathrm{y}^{2}}}=\frac{\mathrm{x}}{\sqrt{\mathrm{x}^{2}+\mathrm{y}^{2}}} \mathrm{y}+ \\
& +\frac{\mathrm{y}((-\mathrm{f}(\mathrm{x})) \mathrm{y}-\mathrm{g}(\mathrm{x}))}{\sqrt{\mathrm{x}^{2}+\mathrm{y}^{2}}} \leq \frac{1}{2} \sqrt{\mathrm{x}^{2}+\mathrm{y}^{2}}+\frac{C y^{2}+\mathrm{C}_{1} \mathrm{xy}}{\sqrt{\mathrm{x}^{2}+\mathrm{y}^{2}}} \leq \mathrm{C}_{2} \sqrt{\mathrm{x}^{2}+\mathrm{y}^{2}}
\end{aligned}
$$

Therefore, the first of the inequalities in the theorem holds true.
In order for the second inequality to be satisfied, it is sufficient to show that for some $\mathrm{C}_{3}>0$.

$$
\sqrt{x^{2}+\left(y+I_{i}(x, y)\right)^{2}}-\sqrt{x^{2}+y^{2}} \leq C_{3} \sqrt{x^{2}+y^{2}}
$$

The inequality (19) is equivalent to the following

$$
\begin{aligned}
& \mathrm{x}^{2}+\left(\mathrm{y}+\mathrm{I}_{\mathrm{i}}(\mathrm{x}, \mathrm{y})\right)^{2} \leq\left(\mathrm{C}_{3}+1\right)^{2}\left(\mathrm{x}^{2}+\mathrm{y}^{2}\right) \\
& \text { But } \\
& \mathrm{x}^{2}+\mathrm{y}^{2}+2 \mathrm{yI}_{\mathrm{i}}(\mathrm{x}, \mathrm{y})+\mathrm{I}_{\mathrm{i}}^{2}(\mathrm{x}, \mathrm{y}) \leq \mathrm{x}^{2}+2 \mathrm{y}^{2}+2 \mathrm{I}_{\mathrm{i}}^{2}(\mathrm{x}, \mathrm{y}) \leq \\
& \leq \mathrm{x}^{2}+2 \mathrm{y}^{2}+2 \mathrm{~K}\left(\mathrm{x}^{2}+\mathrm{y}^{2}\right) \leq(2+2 \mathrm{~K})\left(\mathrm{x}^{2}+\mathrm{y}^{2}\right)
\end{aligned}
$$

and if $\left(\mathrm{C}_{3}+1\right)^{2}>(2+2 \mathrm{~K})$, or $\mathrm{C}_{3}>\sqrt{2+2 \mathrm{~K}}-1$, then the second inequality in (9) is satisfied. So, using Theorem 3, we get that the process, defined by the equation (17) exists for all $\mathrm{t} \geq \mathrm{t}_{0}$, if $\xi(\mathrm{t})-$ is an absolutely locally integrated stochastic process.

\section{REFERENCES}

1. Samoilenko, A.M. and N.A. Perestyuk, 1995. Impulsive differential equations. Singapore, New Jersey, London, World Scientific, pp: 492.

2. Samoilenko, A.M. and Yu. V. Teplinky, 1993. Countable systems of differential equations. Kiev: The Institute of Mathematics, pp: 308 (Russian).

3. Plotnikova, N.V., 2004. The periodical solutions of linear impulse differential inclusions. Nonlinear Oscillations, 7: 495-515 (Russian).

4. Kulev, G.R. and D.D. Bainov, 1993. Lipschitz quasistability of impulsive differential equations. I. Math. Anal. and Appl., 172: 24-32.

5. Rao, A.N.V. and C.P. Tsokos, 1995. Stability behavior of impulsive stochastic differential systems. Dynamic. Systems and Appl., 4: 317-328.

6. Hasminskiy, R.Z., 1969. The stability of the systems of differential equations with random perturbations of their parameters. Moscow, Science, pp: 365 (Russian). 